\title{
Influence of high temperature hold times on the fatigue crack propagation in Inconel 718
}

\author{
David Gustafsson, Johan Moverare, Sten Johansson, Kjell Simonsson, \\ M Hornqvist, T Mansson and Sören Sjöström
}

\section{Linköping University Post Print}

N.B.: When citing this work, cite the original article.

Original Publication:

David Gustafsson, Johan Moverare, Sten Johansson, Kjell Simonsson, M Hornqvist, T Mansson and Sören Sjöström, Influence of high temperature hold times on the fatigue crack propagation in Inconel 718, 2011, International Journal of Fatigue, (33), 11, 1461-1469.

http://dx.doi.org/10.1016/j.ijfatigue.2011.05.011

Copyright: Elsevier http://www.elsevier.com/

Postprint available at: Linköping University Electronic Press

http://urn.kb.se/resolve?urn=urn:nbn:se:liu:diva-70317 


\title{
Influence of high temperature hold times on the fatigue crack propagation in Inconel 718
}

\author{
D. Gustafsson ${ }^{1}$, J.J. Moverare ${ }^{1,1}$, S. Johansson ${ }^{1}$, K. Simonsson ${ }^{1}$, M. \\ Hörnqvist $^{1}$, T. Månsson ${ }^{1}, \mathrm{~S}$. Sjöström ${ }^{1}$ \\ ${ }^{a}$ Division of Solid Mechanics, Department of Management and Engineering, Linköping \\ University, SE-58183 Linköping, Sweden \\ ${ }^{b}$ Division of Engineering Materials, Department of Management and Engineering, \\ Linköping University, SE-58183 Linköping, Sweden \\ ${ }^{c}$ Siemens Industrial Turbomachinery AB, SE-61283 Finspång, Sweden \\ ${ }^{d}$ Volvo Aero Corporation, SE-46181 Trollhättan, Sweden
}

\begin{abstract}
High temperature fatigue crack growth in Inconel 718 has been studied at the temperatures $450^{\circ} \mathrm{C}, 500^{\circ} \mathrm{C}, 550^{\circ} \mathrm{C}$ and $650^{\circ} \mathrm{C}$. The tests were conducted both without hold times and with hold times of different lengths and with a mix of both. Focus has been on quantifying the effect the hold time has upon the crack growth rate and how much it damages the material. Furthermore, it has been investigated how this damage influences the actual cracking behaviour, i.e. where in the loading cycle the damage contributes most to the crack growth. This damage is related to the concept of a damaged zone in front of the crack tip. The size of the damaged zone has been derived from the tests and a microscopy study to confirm the findings has also been carried out. It is found that the concept of a damaged zone can be a successful explanatory model for the observed crack growth behaviour under high temperature hold time.
\end{abstract}

${ }^{*}$ Corresponding author. Tel: $+46(0) 13281175$

Preprint submitted to International Journal of Fatigue

December 15, 2011 
Keywords: nickel-base superalloys, fatigue crack propagation, Inconel 718, hold times, grain boundary embrittlement

\section{Introduction}

In gas turbines it is important to design for as high gas temperatures as possible in order to attain a high thermal efficiency [? ]. For jet engines, an increased temperature opens up for higher payloads, speed increase and a greater range. In the case of power generating gas turbines, the increase of temperature leads to lower fuel consumption, reduced pollution and thus lower costs [? ]. The high-temperature load carrying ability of critical components is therefore one of the most important factors that set the limits in gas turbine design. Even though high temperature resistant superalloys are used, hot components are usually designed to run near their temperature and load limits. Uncertainties in models and methods used for fatigue life prediction under these circumstances are thus very problematic. Among the most important questions in gas turbine design today is therefore how to predict the life of such components.

In gas turbine design, the main load cycle is typically defined by the start up and shut-down of the engine. The loading varies from component to component but often it is a combination of both temperature variations and mechanical loads. These two events defining the main load cycle are separated by a few hours in the case of an aero engine and weeks or months in turbines for power generation. Models used for the LCF calculation are generally based on the stress or strain and temperature fields defined by these events together with isothermal material properties corresponding to the peak temperature. This approach follows the assumption of linear damage accumulation, and implies that the load sequence will have no importance, that all load cycles can be identified by a cycle counting procedure (e.g. Rain-flow, range pair etc) and that the total damage can be found by a simple summation of the damages from each load cycle. However, it is well known from laboratory experiments 
that the introduction of hold times (with constant load) at high temperature may, for some materials and circumstances, strongly influence the LCF life as compared to the case of a continuous cycling [? ]. Therefore, not only the turning points of the main load cycle are of importance when deciding the LCF life of a gas turbine component.

Focusing attention on the physical origins of the material degradation, one notes the cyclic plastic deformation [? ], which inevitably will accompany the unloading and reloading cycles. In addition, when the hold time temperature is high enough, it can cause time dependent effects such as creep deformation [? ]. Another complicating fact is that the mechanical properties degrade during long time exposure to high temperature by e.g. microstructural changes, oxidation and grain boundary embrittlement [? ], thus reducing the fatigue resistance of the material. When searching for a model for predicting the interaction between cyclic damage, creep and embrittlement of the material for use in an industrial design process, the following requirements will appear:

- The interaction between the time dependent and cyclic load need to be separated via a cycle counting procedure

- A damage accumulation between the time dependent damage and the cyclic damage must be possible

Furthermore, such an approach must also be applicable to situations at which the crack growth contributions from the hold time load and the cyclic load are of the same order, since this is the region where it is deemed possible to design gas turbine parts. Should e.g. the hold time effect dominate totally it is expected that the LCF life is very short and we are in such a case not faced with an analysis problem but rather a design problem.

When setting up and calibrating a model to be used in determining the robustness of a part with respect to defects present from production or created as a result of cyclic load, a relevant experimental database is of utmost importance. 
In the following a set of experiments will be presented, which are aimed at providing the basis for a model of the type discussed above. However, the modelling issue will not be addressed in this paper, but will be reported elsewhere.

In detail, the growth of semi-elliptic surface cracks in test specimens of Inconel 718 has been studied under isothermal conditions at the temperatures $450^{\circ} \mathrm{C}$, $500^{\circ} \mathrm{C}, 550^{\circ} \mathrm{C}$ and $650^{\circ} \mathrm{C}$ under both cyclic loads, cyclic loads with hold times and under a mix of both. Focus has been on quantifying the effect the hold time has upon the crack growth rate and how much it damages the material. This damage, manifested by a damaged zone, as previously introduced by Liu et al. [? ], is investigated and an attempt to quantify it is presented. A special type of tests are run to investigate the size of the damaged zone. Furthermore, it is also investigated how this damage influences the actual cracking behaviour, i.e. where in the loading cycle the damage contributes most to the crack growth. This is accomplished by a procedure, where the crack growth during unloading and reloading and the crack growth during hold time are separated.

\section{Material and experimental procedure}

\subsection{Material data}

The material used in this test series was Inconel 718 , a wrought polycrystalline nickel based superalloy with a large amount of Fe and Cr. Its composition (in weight \%) is presented in Table ??. The material was delivered in the form of bars with a diameter of $25.4 \mathrm{~mm}$ and was solution annealed for $1 \mathrm{~h}$ at $945^{\circ} \mathrm{C}$, followed by ageing at two temperatures, $8 \mathrm{~h}$ at $718^{\circ} \mathrm{C}$ and $8 \mathrm{~h}$ at $621^{\circ} \mathrm{C}$ according to the AMS 5663 standard. The line intercept method was used to estimate the grain size to be approximately $10 \mu \mathrm{m}$, which is representative for forged fine grained gas turbine components, e.g. turbine discs. 
Table 1: Composition of elements for Inconel 718 [? ]

\begin{tabular}{lllllllll}
\hline Element & $\mathrm{Ni}$ & $\mathrm{Cr}$ & $\mathrm{Mo}$ & $\mathrm{Nb}$ & $\mathrm{Al}$ & $\mathrm{Ti}$ & $\mathrm{Fe}$ & $\mathrm{C}$ \\
\hline Weight\% & balance & 19.0 & 3.0 & 5.1 & 0.5 & 0.9 & 18.5 & 0.04 \\
\hline
\end{tabular}

\subsection{Experimental procedure}

Crack growth experiments were conducted on Kb-type specimens with rectangular cross sections of $4.3 \times 10.2 \mathrm{~mm}$, see Fig ??. An initial starter notch of nominal depth $0.075 \mathrm{~mm}$ and total width of $0.15 \mathrm{~mm}$ was generated using electro discharge machining (EDM). Before the high temperature testing was carried out, the specimens were fatigue precracked at room temperature and $R=0.05$, to obtain a sharp semicircular crack with a depth of about $0.2 \mathrm{~mm}$. All tests where interrupted at an approximate crack length of $2.5 \mathrm{~mm}$. The fatigue crack growth testing was then carried out under load control using an MTS servo hydralic machine with a maximum load capacity of $160 \mathrm{kN}$, an Instron 8800 control system and the software WaveMaker. The furnace used was an MTS high temperature furnace with three temperature zones (model 652.01/MTS with a temperature controller of model 409.81). The crack propagation was monitored by the direct current Potential Drop (PD) technique according to ASTM E 647 [? ] using a Matelect DCM-1, 2 channel pulsed DCPD system. A direct current of $10 \mathrm{~A}$ was run through the specimen and the PD signal was measured by probe wires spot welded close to the notch at both sides of it. Additional reference probes were spot welded at the back face of the specimen, far from the notched cross-section. In order to reduce the problems associated with thermo-electrical effects, lack of stability in supplying current and changes in the instrumentation or changes of temperature, a normalized PD value was obtained by dividing the measured PD value with the reference value [? ].

The PD ratio was translated to crack length through an experimentally obtained calibration function based on initial and final crack lengths measured on the fracture surface as well as by measured induced beach marks. The latter were 
obtained by applying different load frequencies, temperatures and environments to the test specimen while performing the crack propagation testing. This gave different colored areas of the fracture surface, where the precrack, the final fracture and two crack lengths in between can be identified, all of these were found to be semi-circular, see Fig ??.

Since the PD-technique does not depend on visual accessibility, it is well suited for special situations like vacuum or high temperature environments. However, since the method has an accuracy of $0,01 \mathrm{~mm}$ crack length, the obtained crack lengths have to be rounded off. This process will give the same crack length to several successive cycles, and one therefore has to select the unique (identical) crack sizes and calculate the corresponding number of cycles through an averaging procedure [? ]. From this the standard crack growth description in terms of $\mathrm{da} / \mathrm{dN}$ versus $\Delta \mathrm{K}$ was set up by using a MATLAB code [? ]. For the hold time tests, $\mathrm{PD}$ values were recorded each $2 \mathrm{~s}$ during the test. One datum point was obtained for each loading cycle using the mean value of the cycle. Finally, the solution for the stress intensity factor $\mathrm{K}$ was analytically obtained using a presolved case for a semi-elliptic surface crack [? ].

In a previous study, Gustafsson et al. [? ] presented some first results regarding the fatigue crack growth behaviour of Inconel 718 with high temperature hold times. A baseline test series and a hold time (HT) test series were performed. The baseline tests where conducted at three different temperatures, $450^{\circ} \mathrm{C}$, $550^{\circ} \mathrm{C}$ and $650^{\circ} \mathrm{C}$, while the hold time tests were done at $550^{\circ} \mathrm{C}$ and $650^{\circ} \mathrm{C}$ for hold time durations of $90 \mathrm{~s}$ and $2160 \mathrm{~s}$.

In order to get a more clear picture of the hold time behaviour, additional baseline and hold time tests (to be reported here) have been performed. These tests where conducted at three different temperatures, $500^{\circ} \mathrm{C}, 550^{\circ} \mathrm{C}$ and $650^{\circ} \mathrm{C}$. For $500^{\circ} \mathrm{C}$, a baseline test and a hold time test with $2160 \mathrm{~s}$ hold time were performed. For $550^{\circ} \mathrm{C}$, a long hold time test with $21600 \mathrm{~s}$ hold time and a pure time dependent crack growth test was performed. For, $650^{\circ} \mathrm{C}$, a pure time 
dependent crack growth test was performed. For the pure crack growth test at $550^{\circ} \mathrm{C}$ a considerably longer start crack of $1.35 \mathrm{~mm}$ was used.

To get indications of the embritteled volume (damaged zone) and its size a special test series was also conducted. In these tests cyclic and hold time loadings were alternated in separate blocks, and they will henceforth be referred to as block tests. In detail they start with a cyclic loading (without hold time) up to a specific crack length, then hold time crack growth up to a specific crack length and then both of these steps again, thus ending with a hold time crack growth period, c.f. Fig ??. Each of the four blocks are run over an equal amount of crack length which for the specified initial and final crack lengths became approximately $0.6 \mathrm{~mm}$. The temperatures and hold times were chosen to correspond to the dittos in the hold time tests. In the block test series four tests were conducted; three at the temperature $550^{\circ} \mathrm{C}$ with the hold time lengths 90 $\mathrm{s}, 2160 \mathrm{~s}$ and $21600 \mathrm{~s}$, respectively and one at the temperature $650^{\circ} \mathrm{C}$ with hold time $90 \mathrm{~s}$. Longer hold times for the temperature $650^{\circ} \mathrm{C}$ was excluded from the block tests due to the difficulty of getting interpretable results as these tests only will run very few cycles.

All tests were done in laboratory air and at load ratio of $R=0.05$, as it has been shown that the effects of hold time periods at positive $R$ values are more severe than at negative $R$ values, c.f. [? ] and [? ]. A summary of the tests is shown in Table ??.

\section{Cyclic crack growth results}

The results in this study are to be seen with respect to the results from the previous study by Gustafsson et al. [? ], where it was found that the crack growth rate increases with increasing temperature and with increasing length of the hold time. It was also shown that baseline tests experienced a primarily trans-granular fracture while for the hold time tests the fracture mode was 
Table 2: Summary of tests

\begin{tabular}{lllll}
\hline Test type & $450^{\circ} \mathrm{C}$ & $500^{\circ} \mathrm{C}$ & $550^{\circ} \mathrm{C}$ & $650^{\circ} \mathrm{C}$ \\
\hline Baseline 0.5 Hz & 2 & 1 & 2 & 2 \\
90 s Hold time & - & - & 1 & 1 \\
2160 s Hold time & - & 1 & 1 & 1 \\
21600 s Hold time & - & - & 1 & - \\
90 s Hold time Block test & - & - & 1 & 1 \\
2160 s Hold time Block test & - & - & 1 & - \\
21600 s Hold time Block test & - & - & 1 & - \\
Time dependent crack growth & - & - & 1 & 1 \\
\hline
\end{tabular}

mainly intergranular.

The new baseline crack growth data (da/dN vs $\Delta \mathrm{K})$ for $500^{\circ} \mathrm{C}$ with trendlines for $450^{\circ} \mathrm{C}, 550^{\circ} \mathrm{C}$ and $650^{\circ} \mathrm{C}$ is found in Fig ??. As can be seen the growth rate increases with increasing temperature. The new hold time crack growth data $(\mathrm{da} / \mathrm{dN}$ vs $\Delta \mathrm{K})$ for $500^{\circ} \mathrm{C}$ with $2160 \mathrm{~s}$ hold time with trendlines for $550^{\circ} \mathrm{C}$ and $650^{\circ} \mathrm{C}$ is found in Fig ??. It is seen that the crack growth rate increases with increasing temperature. It is also to be noted that, when constructing the trendlines, all regions with transient behaviour were excluded.

Hold time crack growth data for $550^{\circ} \mathrm{C}$ with hold time $21600 \mathrm{~s}$, is found in Fig ??. For comparison, the trendlines for the $90 \mathrm{~s}$ and $2160 \mathrm{~s}$ hold time tests and the baseline test are also plotted in the figure. It is seen that the crack growth rate increases with increasing hold time duration.

The block test crack growth data (da/dN vs $\Delta \mathrm{K})$ for temperature $550^{\circ} \mathrm{C}$ are found in Fig ??. When a hold time block is applied, the crack growth rate increases dramatically. It is also seen that the crack growth rate increases with increasing hold time duration. The trendlines for the associated hold time tests and base line tests are also plotted in the figure. As can be seen, when there is a shift from base line crack growth to hold time crack growth, a transient 
behaviour is seen, where the crack growth rate increases and stabilizes on the level associated with the hold time crack growth. Similar to this, when a shift from hold time crack growth to baseline crack growth is introduced, a transient behaviour can also be seen. The crack growth rate is reduced successively until it reaches a steady state behaviour corresponding to the baseline crack growth rate.

The block test crack growth data (da/dN vs $\Delta \mathrm{K}$ ) for temperature $650^{\circ} \mathrm{C}$ show similar results as for the tests performed at $550^{\circ} \mathrm{C}$, see Fig ??.

\section{Concept of a damaged zone; mechanisms and experimental findings}

It has in [? ], as well as in [? ]-[? ], previously been shown that there are two different regimes of active fracture mode in Inconel 718 at these types of tests. Basically, for cyclic tests the active fracture mode is mainly transgranular cracking, while for hold time tests the active fracture mode is mainly intergranular cracking. The same phenomena can also be found in other nickel-based superalloys i.e. in Waspalloy [?].

When the crack growth during the hold time was separated from the crack growth occurring during the unloading and reloading, it was concluded in [? ] that significant embrittelment of the grain boundaries must have occurred. This aspect will be further discussed below.

\subsection{Mechanisms}

The underlying mechanisms of the interaction between oxygen and the crack tip material is still not fully understood. However, two dominating theories can be found: stress accelerated grain boundary oxidation (SAGBO) and dynamic embrittlement (DE) [? ]. The SAGBO process involves oxidation of grain boundaries ahead of the crack tip and subsequent cracking of the oxide, 
exposing new surfaces to the oxygen. The DE theory on the other hand advocates embritteling of the grain boundary by oxygen diffusion, separation of the embritteled boundaries and subsequent oxidation of the fresh surfaces. DE requires oxygen diffusion over very short distances, which has been shown to be consistent with the rapid halting of a crack growing under sustained load when the oxygen pressure is removed [? ]. Also the intergranular cracking has also been shown to be dependent on the oxygen partial pressure [? ]. An extensive review of gas phase embrittlement [? ] favors DE as the mechanism behind enhanced sustained load crack growth in superalloys, even though the details of the environmental interactions during cyclic loading may well be more complicated. Studies by Andrieu et al. [? ] and Molins et al. [? ] have indicated that the short range interaction kinetics may be controlled by oxide formation at the crack tip, where the growing oxide may permit or deny oxygen penetration (formation of $\mathrm{NiO}$ with associated vacancy formation to aid penetration and transport of oxygen, and/or formation of passive Chromium oxides, all depending on oxygen pressure and temperature). With increasing time, the oxide will grow thicker and reduce the effective oxygen partial pressure at the crack tip. However, the cyclic loading will repeatedly (depending on waveform) break up the oxide, leaving the crack open to further oxygen attack. In addition to these purely chemical factors, the often complex interactions between stress state and creep relaxation at the crack tip as well as the alloy composition will also affect the crack propagation process [? ]. Furthermore, the grain boundary structure may have an influence of the crack propagation behaviour in cases of embritteling mechanisms as described above.

\subsection{Investigation of the damaged zone}

\subsubsection{Size of the damaged zone}

Regardless of which of the embritteling mechanisms described above that are active in the tests, it is only in a limited volume of the material in front of and 
around the crack tip that they are active; this region is henceforth referred to as the damaged zone. The block tests were designed to investigate the approximate size and mechanical effect of this damaged zone. The larger crack growth rates compared to the baseline tests found in the transients after the hold time period in the block tests (cf. Figs ?? and ??), can be interpretated as a manifestation of a damaged region, where the embrittlement affects the fatigue crack growth behaviour. It is believed that during this transient, the cyclic crack growth progressively propagate through the damaged zone. Thus, it is belived that the length of this transient can represent an approximate measure of the length of the damaged zone, see Table ??. For the block test with $21600 \mathrm{~s}$ hold time at $550^{\circ} \mathrm{C}$ no real stabilized state were reached, thus no transient length is given for this test. Anyway, it may be concluded that the damaged zone is growing with hold time duration and temperature.

Table 3: Length of damaged zone

\begin{tabular}{ll}
\hline Test type & length $[\mathrm{mm}]$ \\
\hline $550^{\circ} \mathrm{C} 90 \mathrm{~s}$ Hold time Block test & 0.05 \\
$650^{\circ} \mathrm{C} 90 \mathrm{~s}$ Hold time Block test & 0.30 \\
$550^{\circ} \mathrm{C} 2160 \mathrm{~s}$ Hold time Block test & 0.20 \\
\hline
\end{tabular}

At the start of each hold time block a transient behaviour with an increasing crack growth rate can clearly be seen. This transient can also be seen at the start of other tests with hold time, and may be interpreted as the inverse of the above described transient at the start of a block with cyclic loading. During this transient it is believed that the damaged zone is rapidly evolving up to a steady state level.

\subsubsection{Basic crack growth behaviour in hold time tests}

To investigate how much the grain boundaries have been weakened, a comparison of the amount of crack growth found at each unloading and reloading and 
during each hold time were done for the hold time tests. When crack length is plotted as a function of time, it is found that a significant part of the cracking takes place during the unloading and reloading of the test specimen. Figure ?? shows the results for $650^{\circ} \mathrm{C}$ with $90 \mathrm{~s}$ hold time. Around a crack length of $2.3 \mathrm{~mm}$, the crack growth during unloading and reloading can be seen to be in the range of $0.05-0.1 \mathrm{~mm}$. This can be compared to the crack growth at the corresponding crack length in a basline test which is approximately 0.0016 $\mathrm{mm} /$ cycle. At this crack length for this particular test the crack growth during unloading and reloading is about $75-80 \%$ of the total crack growth during the cycle. For $550^{\circ} \mathrm{C}$, the previous described behaviour is also found in the tests with longer hold times, $2160 \mathrm{~s}$ and $21600 \mathrm{~s}$, see Figs ?? and ??. For $90 \mathrm{~s}$ hold time at $550^{\circ} \mathrm{C}$, the resolution of the PD-method was to low too be able to draw any conclusions about the separation.

Fig ?? shows the results for the hold time test at $650^{\circ} \mathrm{C}$ with $2160 \mathrm{~s}$ hold time. The first part exposes a behaviour according to previous discussions, but for the later parts in the test a very rapid crack growth takes place. The crack grows from $0.8 \mathrm{~mm}$ to the final crack lengt of $2.5 \mathrm{~mm}$ in just 3 cycles. The interesting thing here is not the crack growth during unloading and reloading but rather the crack growth during the actual hold times. It seems that for higher values of $\Delta \mathrm{K}$ and for higher temperatures the largest contribution to the crack growth will be found during the hold times.

In all tests where it is possible to see the sudden crack growth during unloading and reloading, it is also seen that the initial time dependent crack growth during the hold time is heavily retarded compared to the end of the previous cycle. An interpretation of this is that when an unloading and reloading takes place part of the damaged zone is broken, and the crack tip is once more in a less damaged material. Thus, this indicates that not only the crack growth during load reversals is affected by the embrittlement, but also the crack growth during hold times. 


\subsubsection{Quantitative separation of crack growth in the loading cycle}

A method to separate the crack growth during unloading and reloading from the crack growth during the hold time was set up in an attempt to further investigate and quantify how much of the crack growth that takes place during each of these phases. More specifically, a filtering process was first applied in order to reduce the scatter in the raw data, and then a MATLAB program was used to sort out the amount of crack growth during the hold time and the load reversal. In this analysis we have chosen to plot all parts as functions of $\Delta \mathrm{K}$ although Kmax would have been a better choice for the hold time part. This will however not affect the the results to a large extent as the tests are run with a small $\mathrm{R}$-value, $\mathrm{R}=0.05$.

In each cycle the total amount of crack growth, the crack growth during the hold time and the crack growth during load reversal are calculated. This data is then as described above, plotted in da/dN vs. $\Delta \mathrm{K}$ diagrams for the tests at $550^{\circ} \mathrm{C}$ with $2160 \mathrm{~s}$ and $21600 \mathrm{~s}$ hold time, see Figs ?? and ??, and for $650^{\circ} \mathrm{C}$ with $90 \mathrm{~s}$ hold time, see Fig ??. The tests at $550^{\circ} \mathrm{C}$ with $90 \mathrm{~s}$ hold time and at $500^{\circ} \mathrm{C}$ with $2160 \mathrm{~s}$ hold time were excluded since, despite the filtering process, it was difficult to identify any separation of the crack growth. The hold time test at $650^{\circ} \mathrm{C}$ with $2160 \mathrm{~s}$ hold time was excluded since the test is mostly in the transient region in which it is difficult to see the separation.

As can be seen in Fig ??, the crack growth for the hold time test at $550^{\circ} \mathrm{C}$ with $2160 \mathrm{~s}$ dwell time is dominated by the crack growth during load reversal. On the other hand, for the hold time test at $550^{\circ} \mathrm{C}$ with $21600 \mathrm{~s}$ dwell time, see Fig ??, the crack growth is about equally distributed between crack growth during load reversal and hold time, respectively. In the later parts of the test it even is mainly dominated by the crack growth during hold time. As described above, the crack growth during hold time is retarded by an unloading and reloading. However, for this test the hold time seems long enough give a considerable contribution to the total crack growth in each loading cycle. For the hold time 
test at $650^{\circ} \mathrm{C}$ with $90 \mathrm{~s}$, see Fig ??, the crack growth is once more clearly dominated by the unloading and reloading. This is probably due to the short hold time and the above described retardation effect of the crack growth during hold time due to unloading and reloading.

Thus it seems that crack growth during the hold time becomes more dominant as the dwell time increases. It is also to be noted that, for all tests, the contribution from crack growth during the hold time becomes more dominant as the tests proceed.

For the block tests, each block of hold times was analyzed separately. The results for $550^{\circ} \mathrm{C}$ with $2160 \mathrm{~s}$ hold time and for $650^{\circ} \mathrm{C}$ with $90 \mathrm{~s}$ hold time can be found in Figs ?? and ??, respectively. As can be seen similar results are prevailing as for the corresponding hold time tests. The block test at $550^{\circ} \mathrm{C}$ with $21600 \mathrm{~s}$ hold time was excluded since it includes too few cycles to give a good analysis. Furthermore the block test at $550^{\circ} \mathrm{C}$ with $90 \mathrm{~s}$ hold time was excluded since, despite the filtering process, it was difficult to identify any separation of the crack growth exactly as for the corresponding hold time test.

When plotting da/dt vs. Kmax for each hold time test and comparing with da/dt vs. Kmax for the pure time dependent tests, it is revealed that the crack growth process at steady state conditions may be treated by a creep crack growth like description, see Fig ?? for the tests at $550^{\circ} \mathrm{C}$ and Fig ?? for the tests at $650^{\circ} \mathrm{C}$. All tests except one at $550^{\circ} \mathrm{C}$ with $90 \mathrm{~s}$ hold time converge to the pure time dependent crack growth tests. A transient behaviour is seen at the start of both of the purely time dependent crack growth tests. An interpretation of this is that during this transient the damaged zone is rapidly evolving up to a steady state level, in the same way as the transient seen at the start of each hold time block in the block tests. It is to be noted, that this behaviour is not an indication of a threshold value. It also seems that it does not matter if it is the crack growth during unloading and reloading or if it is the crack growth during the hold time that contributes most, they will essentially balance each 
other. This fit well with the concept of a damaged zone as the crack growth behaviour can be viewed to closely follow the evolution of this zone. Thus, the damaged zone controls the crack propagation process and this is also the reason why all hold time tests converge to the associated time dependent crack growth curve.

\subsection{Microscopy}

In order to investigate and confirm the presence of a damaged zone ahead of the crack tip, samples from different tests were analyzed using an analytical scanning electron microscope (SEM), Hitachi SU70 operating at 10 or $20 \mathrm{kV}$. The preparation was done by first making an axial cut by a diamond tip cutter, which was followed by grinding and careful mechanical polishing of the surface. No etching was performed on the samples, since contrast was achieved from differences in composition and variations in crystallographic orientation.

As stated previously, the crack growth under hold time conditions is mostly intergranular. Careful examination of the cracked area by using channeling contrast in the SEM also shows evidence of planar slip in the grains surrounding the crack tip, see Fig ??. Such increase in slip density generally leads to an increase in the diffusivity of oxygen along the grain boundaries and therefore the oxygen diffusion depth is expected to be dependent of the crack tip stress intensity range $\mathrm{K}[?]$. In addition, an increase in slip density close to the grain boundary would also imply an increase in the matrix diffusion rate which in turn would lead to a higher propensity for segregation of oxide forming elements (such as Niobium or Nickel) towards the grain boundaries. In Fig ??, the appearance of a grain boundary in front of the crack tip is shown in high magnification, where one can see the damaged zone manifested by oxide particles along the grain boundary. 


\section{Conclusions}

High temperature fatigue crack growth in Inconel 718 has been studied for several different temperatures. The tests were conducted both without hold times and with hold times of different lengths and with a mix of both. Focus has been placed on quantifying the effect the hold time has upon the crack growth rate and how much it damages the material. This damage is related to the concept of a damaged zone present in the vicinity of the crack tip. This damaged zone has been investigated both with respect to its size and how it influences the actual cracking behaviour, i.e. where in the loading cycle the damage contributes most to the crack growth. The main conclusions are:

- When the crack growth during the hold time is separated from the crack growth occurring during the unloading and reloading, one can conclude that a significant embrittelment of the grain boundaries must have occurred, since the crack growth during unloading-reloading is much higher than in the corresponding baseline tests without any hold time.

- The increase in crack length due to an unloading/reloading sequence is gradually decreasing during a cyclic loading block, indicating that the crack tip gradually meets less damaged material. The length of this transient is measured to quantify the amount of damage in the material.

- The transient found at the start of each hold time block is interpreted as a build up of damage up to a steady state level.

- The damage becomes more pronounced with higher temperature and longer hold times.

- In the test series no saturation level of the transient lengths was found.

- The initial time dependent crack growth during the hold time is heavily retarded compared to its magnitude at the end of the previous cycle. This indicates that not only the crack growth during load reversals is affected 
by the damage, but also the crack growth during the hold times. This is also indicated in the pure time dependent crack growth tests which in the context of da/dt vs Kmax, show the same sort of transient behaviour as each hold time block in the block tests.

- For tests with longer hold times the crack growth during the hold time becomes more dominant. It is also to be noted that during each test the contribution from crack growth during the hold time becomes more dominant as the test proceeds.

- For the tests carried out it does not matter from a modelling point of view if it is the crack growth during unloading and reloading or if it is the crack growth during the hold time that contributes most to the total crack growth, they will essentially balance each other and the crack growth can for the situations tested be described by a creep crack growth model.

All these findings indicate that the material is in some way damaged during the hold times. The mechanisms of this damage are not yet fully understood, but this paper has described one way to quantify it.

\section{Acknowledgements}

The authors would like to thank Bo Skoog, Linköping University, for the laboratory work, Babak Sharifimajd, Linköping University, for the evaluation work and, Dr. Magnus Hasselqvist and Dr. Per Almroth, Siemens Industrial Turbomachinery $\mathrm{AB}$, for valuable discussions. This research has been funded by the Swedish Energy Agency, Siemens Industrial Turbomachinery AB, Volvo Aero Corporation, and the Royal Institute of Technology through the Swedish research program TURBO POWER, the support of which is gratefully acknowledged. 
[1] R.C. Reed, The Superalloys - Fundamentals and Applications, Cambridge University Press, Cambridge, 2006.

[2] A. Pineau, S.D. Antolovich, High temperature of nickel-base superalloys A review with special emphasis on deformation modes and oxidation, Engineering Failure Analysis, 16 (2009) 2668-2697.

[3] J.P. Pedron, A. Pineau, The Effect of Microstructure and Environment on the Crack Growth Behaviour of Inconel 718 Alloy at $650^{\circ} \mathrm{C}$ under Fatigue, Creep and Combined Loading, Materials Science and Engineering, 56 (1982) 143-156.

[4] F.V. Antunes, High temperature fatigue crack growth in Inconel 718, Materials at High Temperatures, 17(4) (2000) 439-448.

[5] P.S. Grover, A. SAXENA, Modelling the effect of creep-fatigue interaction on crack growth, Fatigue and Fracture of Engineering Materials and Structures, 22(2) (1998) 111-122.

[6] H. Ghonem, D. Zheng, Depth of intergranular oxygen diffusion during environment-dependent fatigue crack propagation in alloy 718, Materials Science and Engineering 150 (1992) 151-160.

[7] ASME E647-08., Standard test method for measurement of fatigue crack growth rates, Annual Book of ASME Standards, Volume 03.01, West Conshohocken (PA): ASM International.

[8] MATLAB, The Math Works, Natick, USA.

[9] ASTM E740-03., Standard practice for fracture testing with surface-crack tension specimens, Annual Book of ASME Standards, Volume 03.01, West Conshohocken (PA): ASM International.

[10] D. Gustafsson, J.J. Moverare, S. Johansson, M. Hörnqvist, K. Simonsson, S. Sjöström, B. Sharifimajd, Fatigue crack growth behaviour of Inconel 718 
with high temperature hold times, Procedia Engineering, 2(1) (2010) 10951104.

[11] M.S. Gopala Krishna, A.M. Sriramamurthy, V.M. Radhakrishnan, Creep data analyses of a columnar-grained nickel-base superalloy by conventional and $\beta$-envelope methods, Journal of Materials Engineering and Performance, $7(4)(1982) 548-554$.

[12] F. V. Antunes, J. M. Ferreira, C. M. Branco, J. Byrne, Influence of stress state on high temperature fatigue crack growth in Inconel 718, Journal of Materials Engineering and Performance, 24(2) (2008) 127-135.

[13] J.P. Pédrona, A. Pineau, The effect of microstructure and environment on the crack growth behaviour of Inconel 718 alloy at $650^{\circ} \mathrm{C}$ under fatigue, creep and combined loading, Materials Science and Engineering, 56(2) (1982) 143-156.

[14] C.M. Branco, Fatigue behaviour of the nickel-based superalloy IN718 at elevated temperature, Materials at High Temperatures, 12(4) (1994) 261-267.

[15] P. Heuler, E. Affeldt, R.J.H. Wanhill, Effects of Loading Waveform and Stress Field on High Temperature Fatigue Crack Growth of Alloy 718, Materialwissenschaft und Werkstofftechnik, 34(9) (2003) 790-796.

[16] J. Byrne, R. Hall, R. Grabowski, Elevated temperature fatigue crack growth under dwell conditions in Waspaloy, International Journal of Fatigue, 19(5) (1997) 359-367.

[17] D.A. Woodford, Gas phase embrittlement and time dependent cracking of Nickel based superalloys, Energy Materials, 1 (2006) 59-79.

[18] J.A. Pfaendtner, C.J. Jr McMahon, Oxygen-induced intergranular cracking of a Ni-based alloy at elevated temperatures - an example of dynamic embrittlement, Acta Materialia, 49 (2001) 3369-3377. 
[19] H. Ghonem, T. Nicholas, A. Pineau, Elevated Temperature Fatigue Crack Growth in Alloy 718-Part II: Effects of Environmental and Material Variables, Fatigue and Fracture of Engineering Materials and Structures, 16(6) (1993) $577-590$.

[20] E.Andrieu, Intergranular crack tip oxidation mechanisms in nickel-based superalloy, Materials Science and Engineering 154(1) (1992) 21-8.

[21] R. Molins, G. Hochstetter, J.C. Chassaigne, E. Andrieu, Oxidation effects on the fatigue crack growth behavior of alloy 718 at high temperature, Acta Materialia, 45(2) (1997) 663-674.

[22] X.B. Liu, L.Z. Ma, K.M. Chang, E. Barbero, Fatigue Crack Propagation of Ni-based Superalloys, Acta Metallurgica Sinica, 18(1) (2005) 55-64.

[23] U. Krupp, Fatigue Crack Propagation in Metals and Alloys, betz-druck GmbH, Darmstadt, 2007.

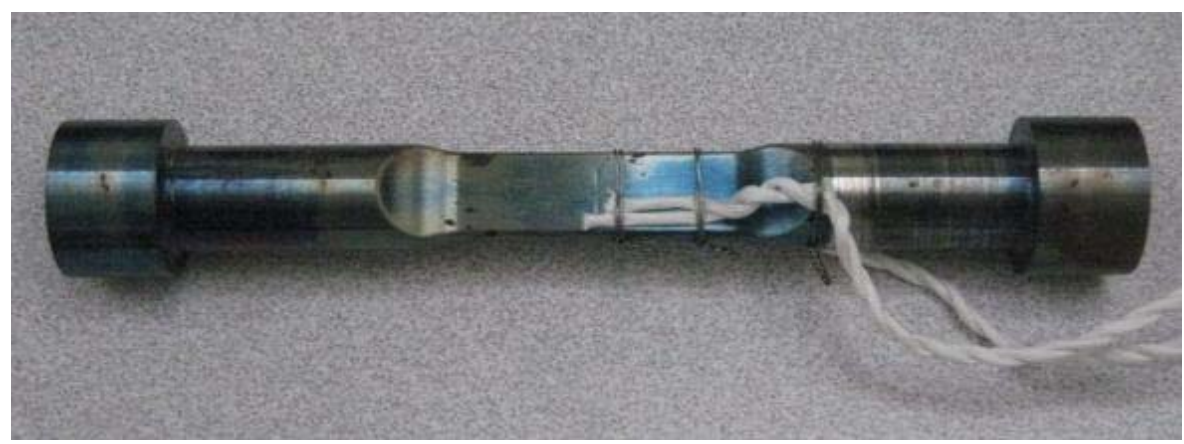

Figure 1: Instrumented Kb-type test specimen 


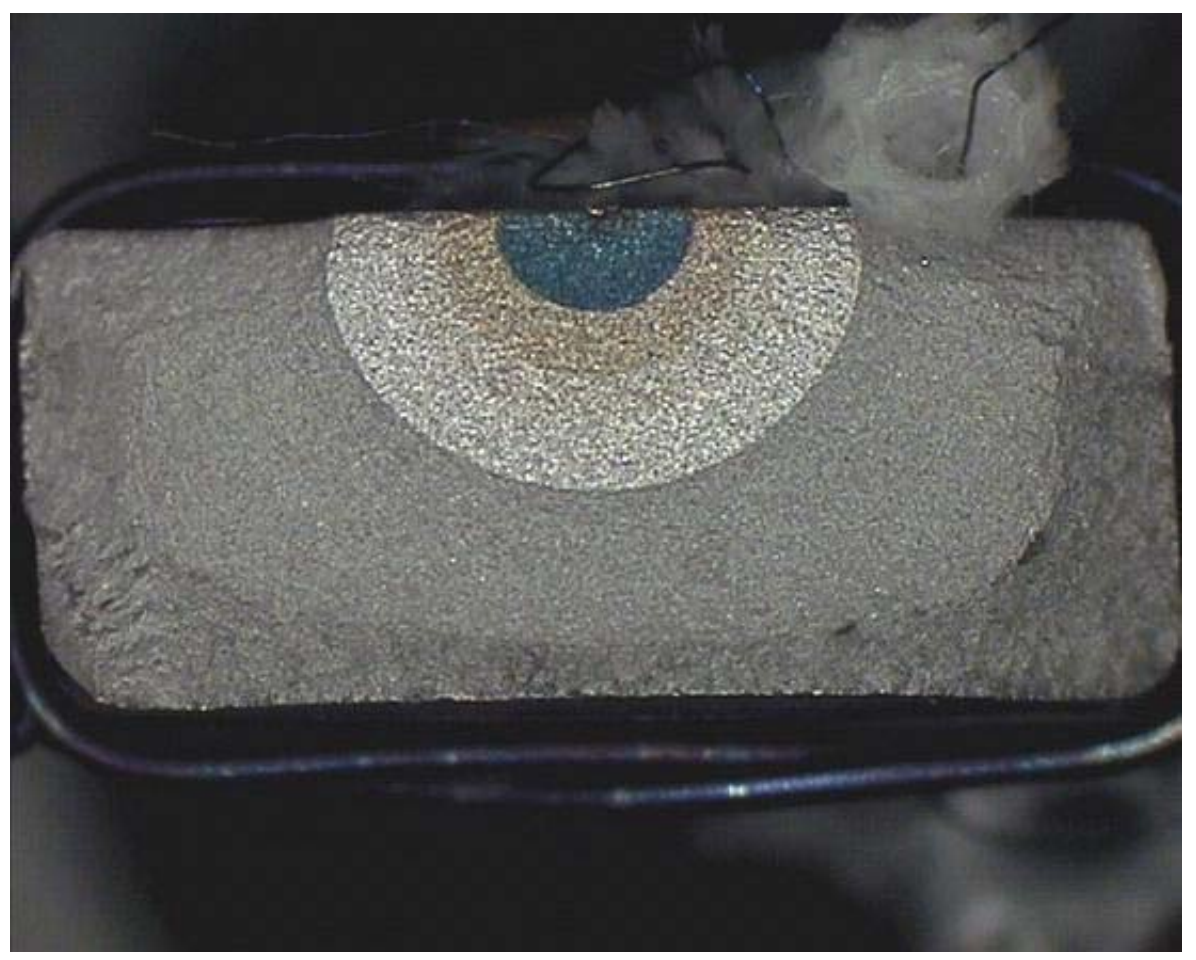

Figure 2: Fracture surface of the calibration specimen with visible beach marks

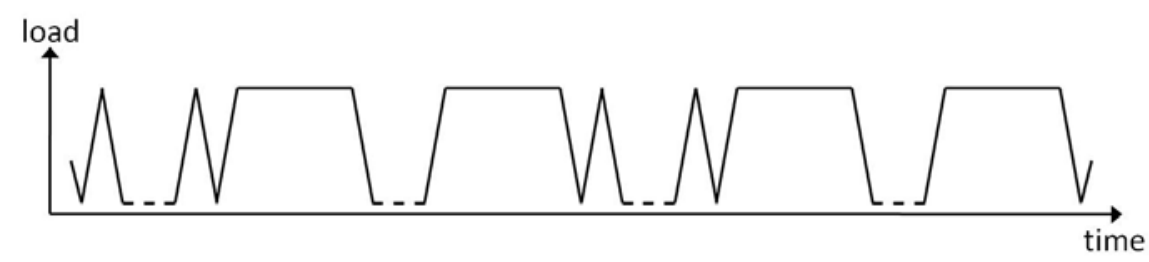

Figure 3: Load-time profiles for block tests 


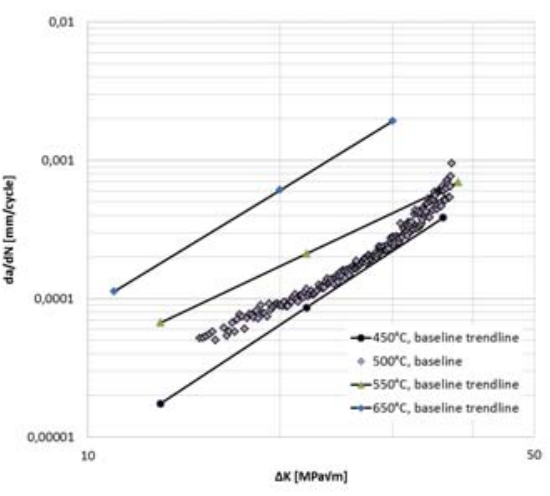

(a) Baseline

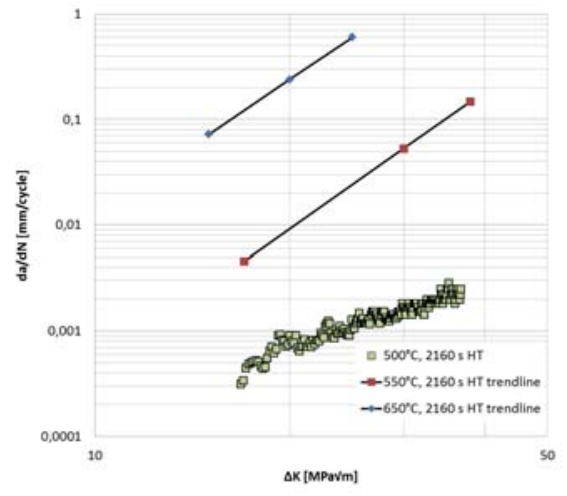

(b) $2160 \mathrm{~s}$ hold time

Figure 4: $500^{\circ} \mathrm{C}$, crack growth data

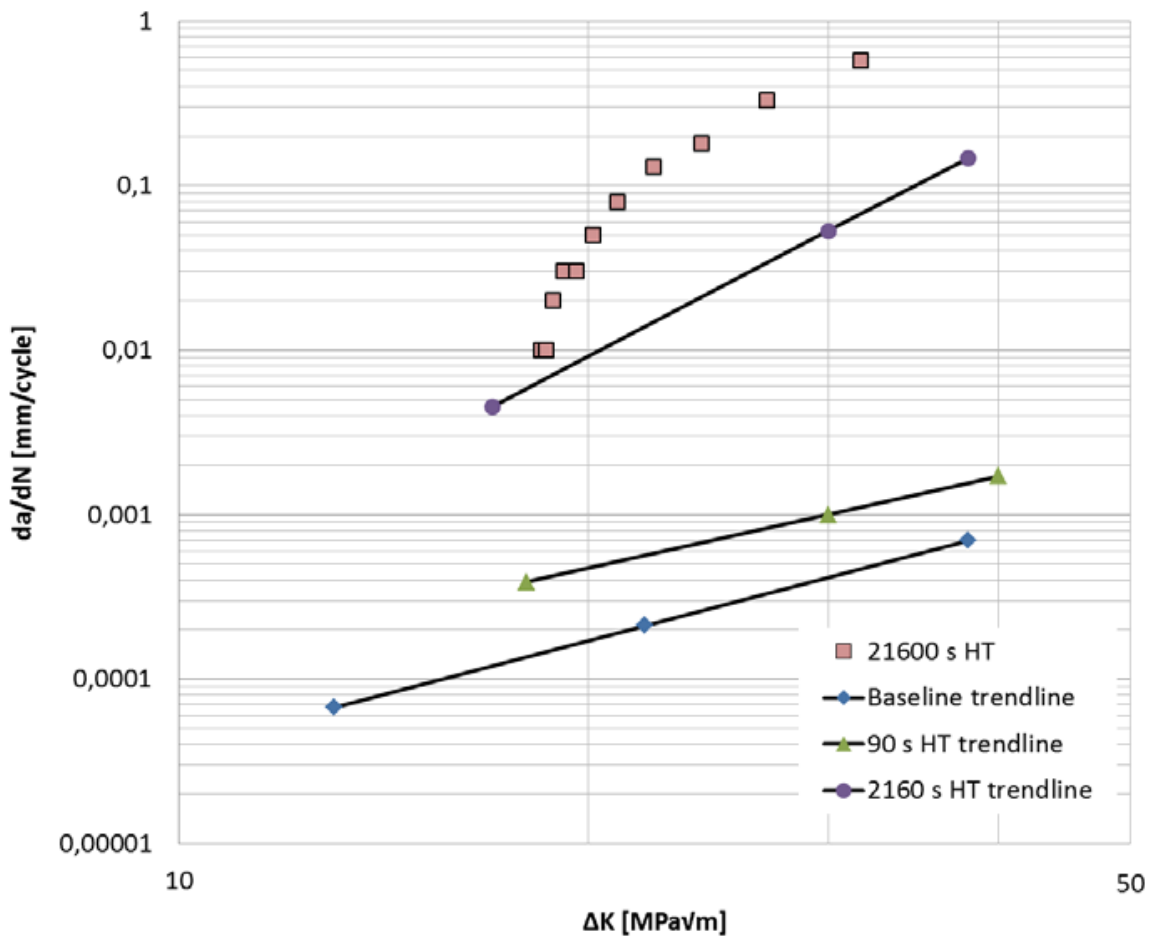

Figure 5: $550^{\circ} C, 21600 \mathrm{~s}$ hold time crack growth data 


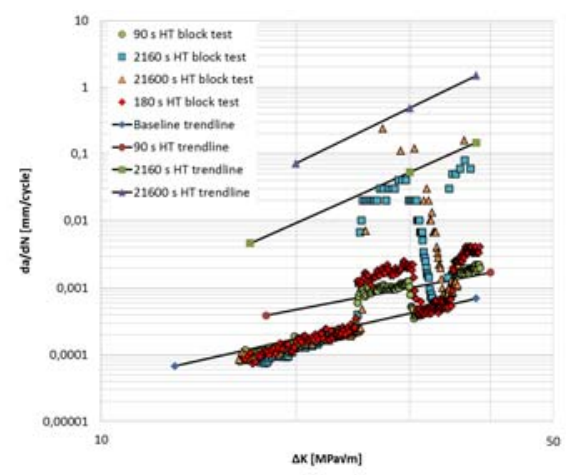

(a) $550^{\circ} \mathrm{C}$

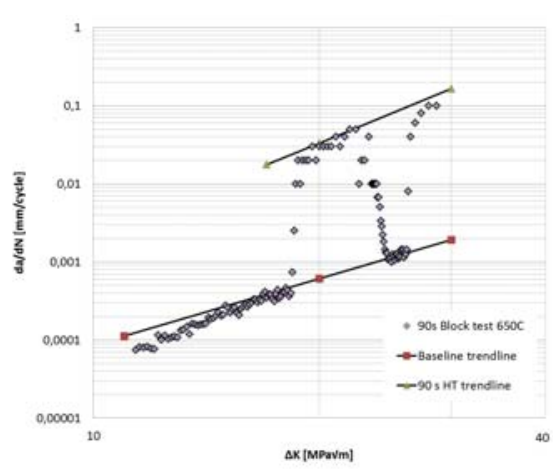

(b) $650^{\circ} \mathrm{C}$

Figure 6: Block test crack growth data

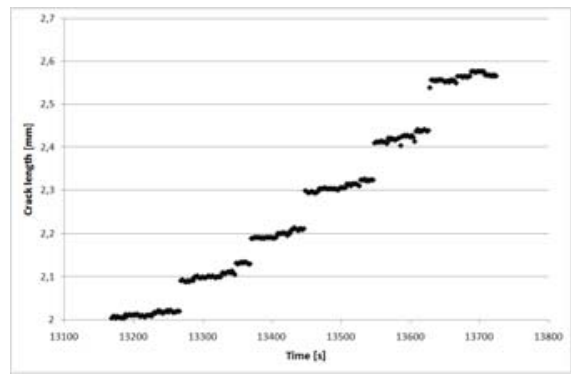

(a) $90 \mathrm{~s}$ hold time

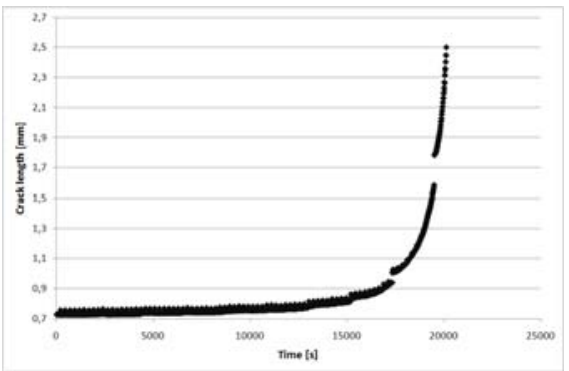

(b) $2160 \mathrm{~s}$ hold time

Figure 7: Crack length vs time for tests at $650^{\circ} \mathrm{C}$

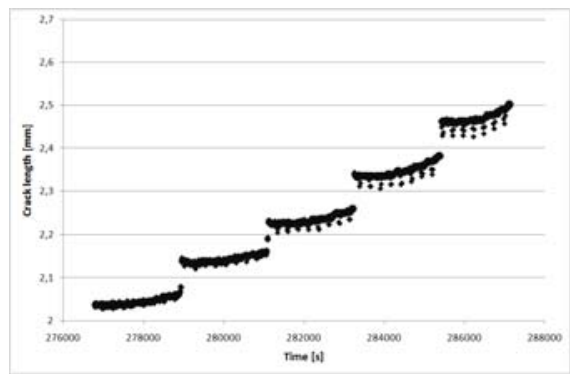

(a) 2160 s hold time

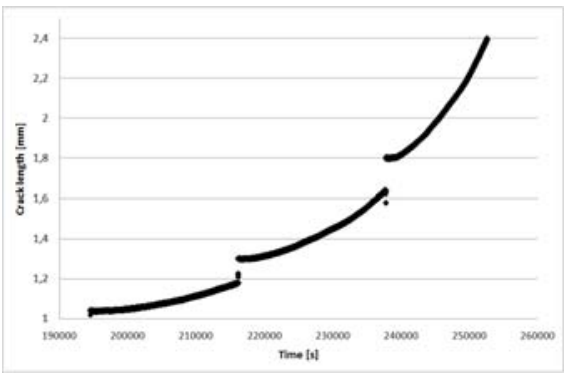

(b) $21600 \mathrm{~s}$ hold time

Figure 8: Crack length vs time for tests at $550^{\circ} \mathrm{C}$ 


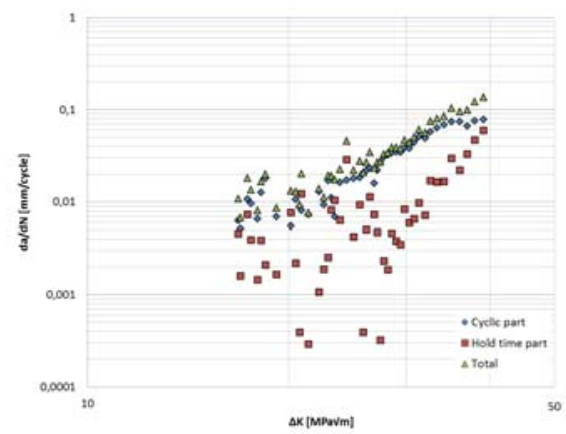

(a) 2160 s hold time

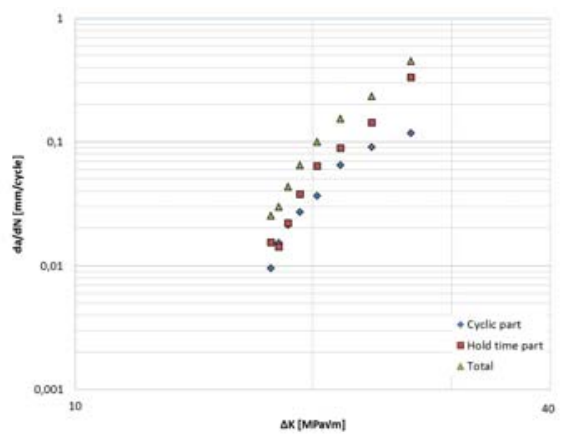

(b) $21600 \mathrm{~s}$ hold time

Figure 9: Separation of crack growth during load reversal and during hold time for tests at $550^{\circ} \mathrm{C}$

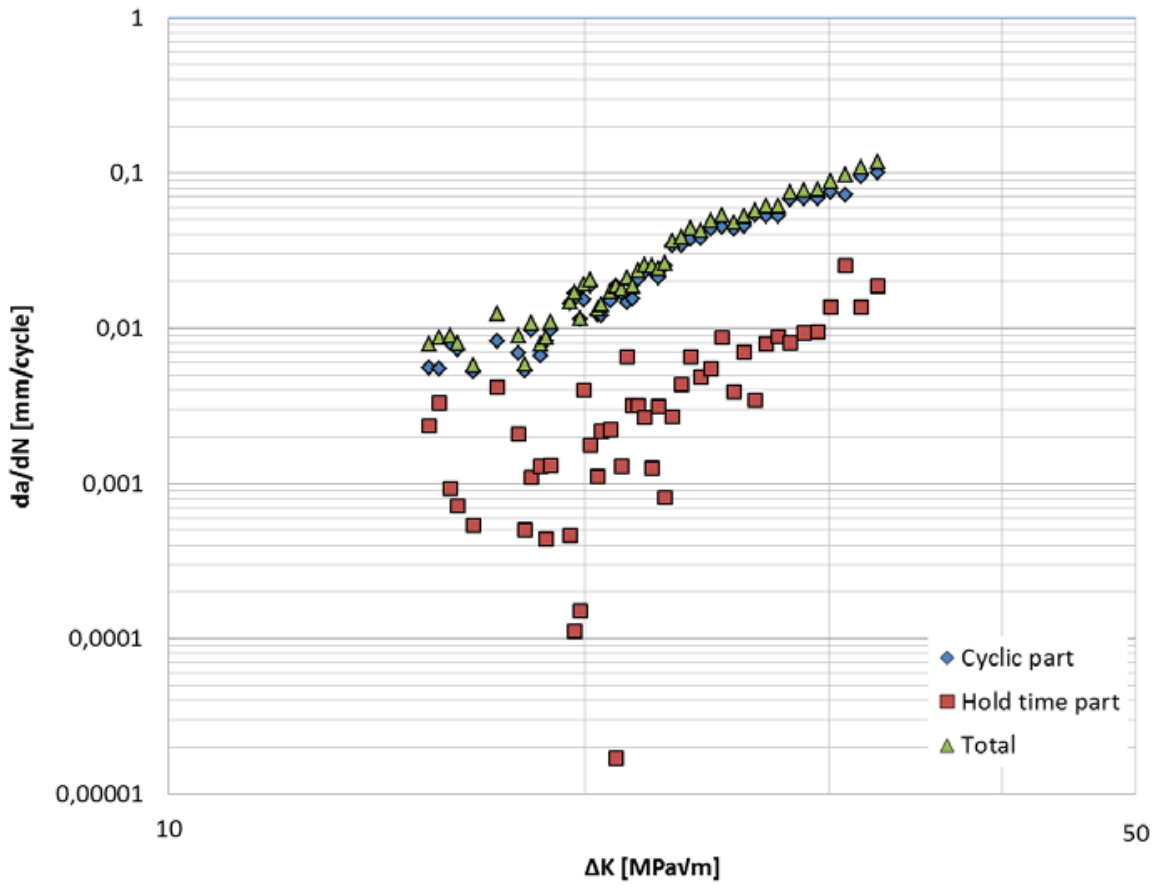

Figure 10: Separation of crack growth during load reversal and during hold time for the test at $650^{\circ} \mathrm{C}$ with $90 \mathrm{~s}$ hold time 


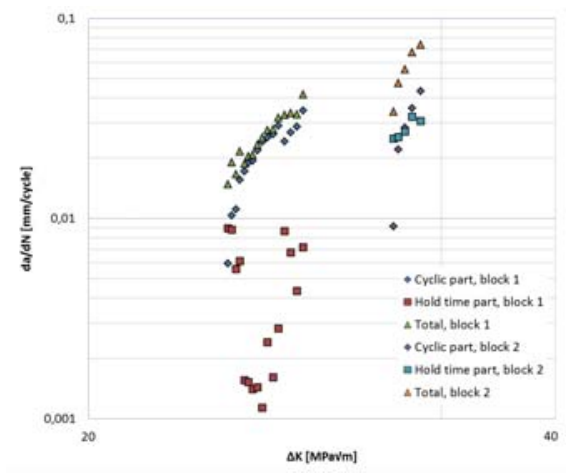

(a) $550^{\circ} \mathrm{C}$ with 2160 s hold time

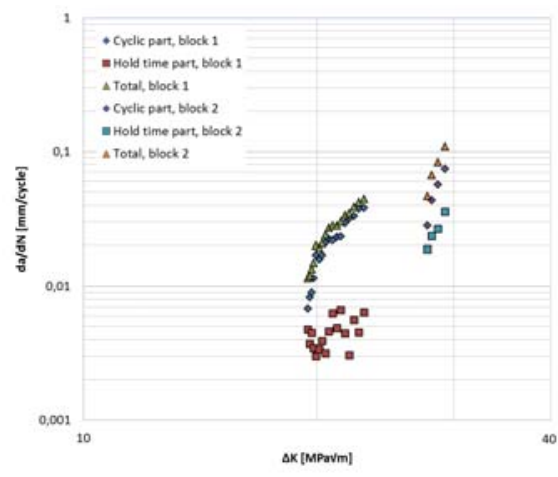

(b) $650^{\circ} \mathrm{C}$ with $90 \mathrm{~s}$ hold time

Figure 11: Separation of crack growth during load reversal and during hold time for the block tests

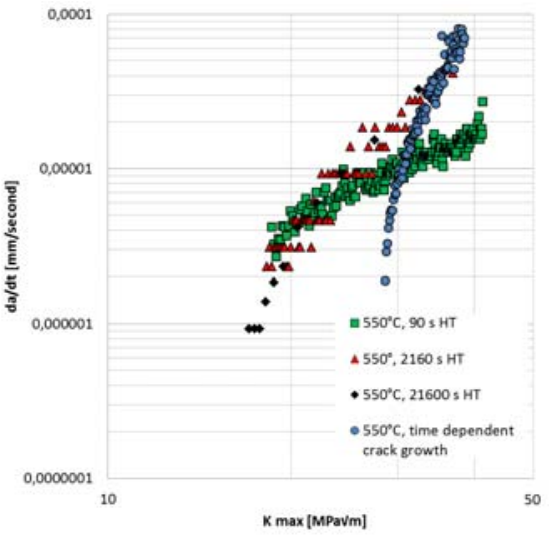

(a) $550^{\circ} \mathrm{C}$

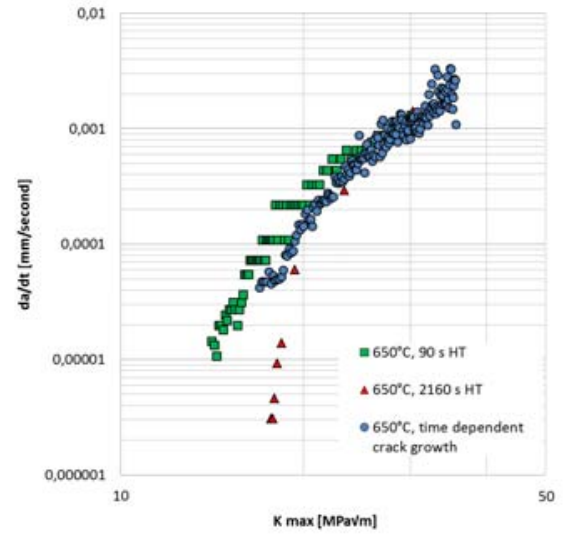

(b) $650^{\circ} \mathrm{C}$

Figure 12: da/dt vs. Kmax for HT tests 

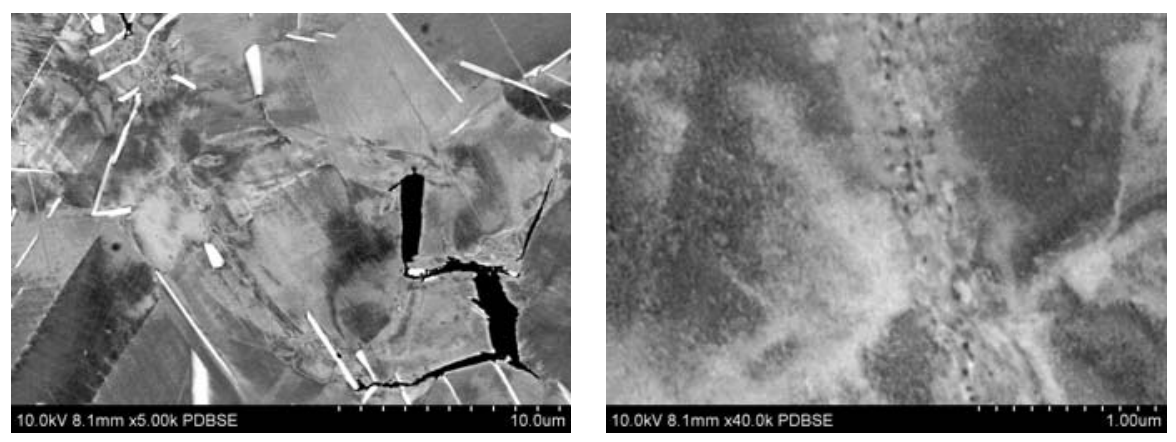

(a) Showing evidence of planar slip in the (b) Showing the damaged zone manifested by grains surrounding the crack tip. the oxide particles along the grain boundary.

Figure 13: Scanning backscatter electron micrograph of test at $550^{\circ} \mathrm{C}$ with 90 s hold time 